\title{
Effect of neem leaf and banana pulp extracts on shelf life and quality of mango (Mangifera indica L.)
}

\author{
Rabeya Akter Sarmin ${ }^{1}$, Shamim Ahmed Kamal Uddin Khan ${ }^{2}$, Kanij Fatema ${ }^{1}$ and Sabiha Sultana ${ }^{2}$ \\ ${ }^{1}$ Department of Food and Nutrition, KCC Women's College, Life Science School, Khulna University, Khulna-9208, Bangladesh \\ ${ }^{2}$ Agrotechnology Discipline, Life Science School, Khulna University, Khulna-9208, Bangladesh
}

\begin{tabular}{|c|c|}
\hline ARTICLE INFO OPEN & Abstract \\
\hline $\begin{array}{l}\text { Article history: } \\
\text { Received: } 14 \text { May } 2018 \\
\text { Accepted: 05 September } 2018 \\
\text { Published: } 31 \text { December } 2018 \\
\text { Keywords: } \\
\text { Mango; Plant Extract; Shelf life; } \\
\text { Microbial infection } \\
\text { Correspondence: } \\
\text { S.A. Kamal Uddin Khan } \\
\text { 凶: samkuk_bd@yahoo.com }\end{array}$ & $\begin{array}{l}\text { The study was carried out to minimize the postharvest loses and extend shelf life of mango fruitby } \\
\text { maintaining physico-chemical properties. The variety selected for the study was "Amrapali". Freshly } \\
\text { harvested mango was treated with different concentrations }(20 \% \text { and } 40 \%) \text { of neem leaf and banana pulp } \\
\text { extract alone or in combination. Untreated mango was considered as control. All treated and untreated } \\
\text { mango was kept into paper cartons at room condition. The treated fruits showed significant differences in } \\
\text { case of total soluble solids content, titratable acidity, vitamin C, disease incidence, disease severity and } \\
\text { shelf life in comparison to control fruits. Among the treatments, T2 (neem leaf extract at } 20 \% \text { ) and T5 } \\
\text { (neem leaf extract } 40 \%+\text { banana pulp extract } 40 \%) \text { treatments showed longer shelf life }(9.92 \text { and } 10.25 \\
\text { days, respectively), slower changes in color (score } 2.77 \text { and } 2.93 \text {, respectively) and firmness (score } 2.67 \\
\text { and } 2.77 \text {, respectively); less disease severity (score } 2.93 \text { and } 3.57 \text {, respectively), disease incidence } \\
(46.67 \% \text { and } 60.00 \%) \text { and lower loss in weight ( } 38.04 \% \text { and } 35.17 \% \text {, respectively) at } 9 \text { DAT (Days after } \\
\text { treatment). On the other hand, total soluble solid was highest in T3 (neem leaf extract } 40 \%) \text { treated } \\
\text { fruitswith18.73\% more Brix at } 13 \text { DAT in comparison to control and other treatments. The effectiveness } \\
\text { of the treatment T5 (neem leaf extract } 40 \%+\text { banana pulp extract } 40 \% \text { ) was meaningful which could be } \\
\text { recommended for maintenance of postharvest quality of mango stored in ambient conditions. }\end{array}$ \\
\hline
\end{tabular}

Copyright:

(c) (1)

(O2018 by authors and BAURES. This work is licensed under the Creative Commons Attribution International License (CC By 4.0).

\section{Introduction}

Mango (Mangifera indica L.) is a delicious, nutritionally superior and one of the most valuable fruits which is a member of the family Anacardiaceae. The mango is the only species that is grown commercially on a large scale. It has a unique position in respect of nutritional quality, taste, consumers' preference etc., among the fifty kinds of fruits grown in Bangladesh (Ahmed and Singh, 2000). It is commercially grown in more than 40 countries. Asia is the main producer with $76.9 \%$ of the world production, followed by USA (13.38\%), Africa (9\%) and Europe (<1\%) (Jacobi et al., 2001). Bangladesh is the world's ninth largest producer of mango after India, China, Thailand, Indonesia, Mexico, Pakistan, Brazil and Philippines (FAO, 2010). About 250 varieties of mango are grown in Bangladesh (Shafique, 2006) though it is commercially cultivated in the districts of Rajshahi, Dinajpur, Rangpur, Kushtia, Satkhira and Jessore (Ferdowsi, 2014). However, profitable mango production is hampered by several challenges, including inappropriate agronomic practices, lack of adequate planting materials, inappropriate pest and disease management technologies, poor extension support systems, poor postharvest handling technologies and poor marketing infrastructure as well as lack of appropriate credit support facilities (Braimah et al., 2010). Because of mishandling, inadequate storage or lack of postharvest technical knowledge, producers and traders have to face about $27 \%$ losses of their fresh produce (Hassan, 2010). The loss of this perishable commodity is estimated up to 320.7 thousand tons annually with a value of Tk. 3,000 lakh in Bangladesh (Haq, 2002). Therefore, it is important to find a practical, cost effective and non-toxic method to prevent decaying of mango. Use of natural plant extracts provides an opportunity to avoid or minimize chemical preservatives.

Plant extracts are available worldwide and can be managed with low cost. In addition, plant extracts have no negative impacts on health (Pervin, 2016). On the other hand, chemicals may cause different harmful impacts on human body. Plant extracts used as postharvest treatment form a thin film around the treated fruit. This film acts as a semi-permiable membrane to regulate the diffusion of oxygen and carbon dioxide into and out of the fruit which ultimately reduce the rate of metabolism and also prevent water loss (Alleyne and Hagenmaier, 2000). Among the plant extracts, neem (Azadirachta indica) extract has been used for centuries in Asia as insecticides and fungicides (Chaturvedi et al., 2003). Azadirachtin is considered as the most active substance in neem which has growth regulating, fungicidal, and insecticidal properties (Schmutterer, 1990) with minimal impact on nontarget organisms and is compatible with other eco-friendly biocontrol agents (Srivastava, 2003). Banana pulp and peel extracts also contain antifungal and antibiotic components (Kumar et al., 2012). 
But rare use of plant extracts as postharvest treatment has been noticed and only a few researches has been done on it in Bangladesh. Considering this situation, the current study was conducted to evaluate the effectiveness of neem and banana extracts in maintaining physico-chemical properties and extending shelf life of mango during postharvest period.

\section{Materials and Methods}

Materials used and experimental design: Fresh matured mango fruit was collected from Dighalia, Khulna. Commercially grown fresh, uniform size and disease free fruits were collected from the mango orchard and transferred to the Horticulture Laboratory, Khulna University. The experiment was laid out in completely randomized design (CRD) with three replications including 10 fruits in each replication. Five treatments were applied on the sample under study where $\mathrm{T} 1=$ Control, $\mathrm{T} 2=$ neem leaf extract $20 \%, \mathrm{~T} 3=$ neem leaf extract $40 \%$, T4 $=$ neem leaf extract $(20 \%)+$ banana pulp extract $(40 \%)$ and $\mathrm{T} 5=$ neem leaf extract $(40 \%)+$ banana pulp extract $(40 \%)$. The experiment was conducted at ambient conditions at $25 \pm 2^{\circ} \mathrm{C}$ temperature and $70 \pm 5 \%$ relative humidity.

Preparation and application of plant extracts: Fresh green leaves of neem (about 250g) were collected from Khulna University campus and blended with $500 \mathrm{ml}$ of distilled water. Then $20 \%$ or $40 \%$ neem leaf extract solution was prepared by taking $60 \mathrm{ml}$ or $120 \mathrm{ml}$ raw neem leaf extract in $500 \mathrm{ml}$ beaker with the addition of $240 \mathrm{ml}$ or $180 \mathrm{ml}$ distilled water separately to make a final volume of $300 \mathrm{ml}$ (Mia, 2003). Similarly, for the preparation of banana pulp extract $(40 \%), 80 \mathrm{~g}$ of pulp was added with $120 \mathrm{ml}$ of distilled water respectively and blended. Finally the extracts solutions were filtered before use and stored in refrigerator at $5^{\circ} \mathrm{C}$.

In case of combined treatments, the mango fruits were treated with $40 \%$ banana pulp extract for 5 minutes and then treated with $20 \%$ or $40 \%$ neem leaf extract according to the treatments. All the treated (individual or combined) and untreated samples were placed on a sterilized surface in five groups for five treatments each containing three replications of 30 fruits.

Data collection and Observation: During the entire experimental period, the treated mango samples were observed every day for physical changes, but chemical changes were measured at one day interval using standard procedures. The physico-chemical changes of samples were observed for two weeks as influenced by different treatments.

Weight loss: Weight loss was determined daily by using a laboratory grade digital weight measuring balance (AND EK600H) which was expressed as percentage of its initial weight and calculated by using following formula as suggested by Knab (2013). The cumulative loss of weight was presented in the article.
Percent of weight loss $(\mathrm{WL})=\frac{\mathrm{IW}-\mathrm{FW}}{\mathrm{IW}} \times 100$

Here, WL= Percent of weight loss, IW= Initial fruit weight $(\mathrm{g}), \mathrm{FW}=$ Final fruit weight $(\mathrm{g})$.

Changes in color and firmness: Changes in color and firmness during storage were determined subjectively on the basis of the characteristics as stated by Dang et al. (2008) with the help of a numerical scaling (scale of 1 to 5 ) where for color $-1=100 \%$ green, $2=1-25 \%$ yellow, 3 = 26-50\% yellow, $4=51-75 \%$ yellow, $5=76-100 \%$ yellow and for firmness- $1=$ Hard, 2 = Sprung, $3=$ Slightly soft, $4=$ Eating soft and $5=$ Over soft.

Total Soluble Solids (TSS) of mango pulp (\% brix): TSS of mango pulp was estimated by using Abbe's refractometer (REF 10/111). A drop of mango juice squeezed from the mango was dropped on the prism of the refractometer. Percent of TSS was obtained as the direct reading from the instrument (Ranganna, 1979).

Titratable acidity (TA) of mango pulp: About $10 \mathrm{ml}$ of freshly extracted juice was diluted with $20 \mathrm{ml}$ of distilled water. Aliquot $(5 \mathrm{ml})$ was titrated against $0.1 \mathrm{~N}$ $\mathrm{NaOH}$ solution using phenolphthalein as an indicator to a pink color end point and expressed as percent malic acid. TA was calculated by using the formula as described by Khan and Singh (2008) is as follows:

Malic acid $(\%)=\frac{0.0067 \times \text { volumeof } \mathrm{NaOH} \times 30 \times 100}{5 \times 10}$

Here, $0.0067=$ Milli-equivalent weight of malic acid, $30=$ Total volume $(\mathrm{ml})$ of solution, 5= Extracted juice sample $(\mathrm{ml}), 10=$ Volume of aliquot $(\mathrm{ml})$.

Determination of vitamin $\mathbf{C}$ content: Vitamin $\mathrm{C}$ content in the sample was determined by the following formula as suggested by Majumdar and Majumdar (2003).

Vitamin $\mathrm{C}=\frac{\mathrm{e} \times \mathrm{d} \times \mathrm{b}}{\mathrm{c} \times \mathrm{a}} \times 100$

Where, $a=$ weight of sample, $b=$ volume made with metaphosphoric acid, $\mathrm{c}=$ volume of aliquot taken for estimation, $d=$ dye factor, $e=$ average burette reading of sample.

Microbial examination: Infected fruit samples were taken in different sterilized petridishes with intensive care to avoid contamination between fruits and examiner's hand. After that a little amount on infected portion was placed on sterilized slide to examine through microscope (Pervin, 2016).

Disease Incidence: The percentage of disease infected mango is called disease incidence. Black spots and visible symptoms were considered as disease. For determining the percentage of infected mango fruit, the infected fruits were counted and calculated using the following equation (Ullah, 2007). 
Disease Incidence $=\frac{\text { Number of infected mango }}{\text { Total number of mango }} \times 100$

Disease severity: The percent of infected fruit area is known as disease severity which was determined with the help of a numerical scaling (scale of 1 to 5) and this estimation was done based on the eye estimation (Ullah, 2007).

Shelf life: Shelf life of mango treated with different treatments was calculated by counting the number of days until the score for color, firmness and disease severity retains less than or equal to 3 . The number of days for attaining a loss of $25 \%$ weight was also considered to calculate shelf life. The average of the days required to reach at the mentioned level of the considered parameters was recorded as the shelf life of fruits.

Statistical analysis: The collected data on various parameters were subjected to analyze the variance
(ANOVA) using STAR (Statistical Tool for Agricultural Research) Version 2.0.1 (IRRI, 2013). Mean comparisons were made using Least Significant Difference (LSD) test at 5\% levels of significance (Gomez and Gomez, 1984).

\section{Results and Discussion}

Effects of neem leaf and banana pulp extract on color change of mango: There was no significant difference among the treatments in respect of color change of the mango fruit under this study. The average increase in color was $79.75 \%$ from 1 DAT to 15 DAT. However, the increase in color change on 3 DAT was pretty sharp in $\mathrm{T} 1$ than all other treatments. The acceptable color limit (3) was noticed in T1for 7 days while it retained three days more in T5 and T2. Lower color score was observed in T5 (score 3.20) than control (score 4.20) at 10 DAT. The other treatments crossed the acceptable limit at 9 DAT (Fig. 1 and Plate 1).

\begin{tabular}{|c|c|c|c|c|c|}
\hline Treatment & $0 \mathrm{DAT}$ & 6 DAT & $10 \mathrm{DAT}$ & 13 DAT & 16 DAT \\
\hline T1 (Control) & & & & & \\
\hline T2 (20\% NLE) & & & & & \\
\hline T3 (40\% NLE) & & & & & \\
\hline $\begin{array}{l}\text { T4 (20\% NLE + } \\
40 \% \text { BPE) }\end{array}$ & & & & & \\
\hline $\begin{array}{l}\text { T5 (40\% NLE + } \\
40 \% \text { BPE) }\end{array}$ & & & & & \\
\hline
\end{tabular}

Plate 1. Changes in color and firmness in Amrapali mango treated with different concentrations of neem leaf extract (NLE), banana pulp extract (BPE) and their combinations

The finding of Ferdowsi (2014) supports the findings of the current study. According to her, neem leaf extract delays color development of mango fruit during storage. Similarly neem leaf extracts lowered color changes of treated guava fruit as observed by Malik et al. (2015).
Effects of neem leaf and banana pulp extract on firmness reduction of the mango: A clear rapid reduction of firmness $(79.75 \%)$ was found in mango from 1 DAT to 15 DAT. The acceptable firmness limit (3) was noticed in T1 for 7 days while T2, T4 and T5 treated fruits crossed the acceptable limit at 10 DAT of 
storage period. However, there was no significant difference observed between $\mathrm{T} 2, \mathrm{~T} 4$ and $\mathrm{T} 5$. The highest average reduction in firmness was noticed in $\mathrm{T} 1$ (score 3.06) and lowest in T5 (score 2.56) where T1 showed 1.20 -fold higher reduction than T5 at 15 DAT (Fig. 2 and Plate 1).
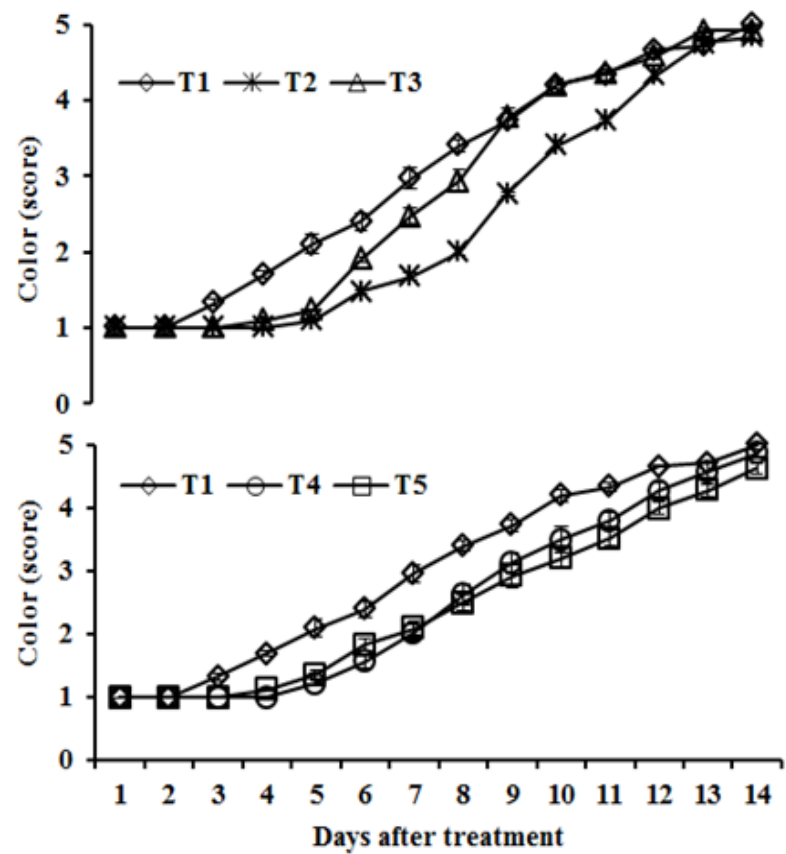

Fig. 1. Change in color of mango due to postharvest treatment with neem leaf and banana pulp extracts
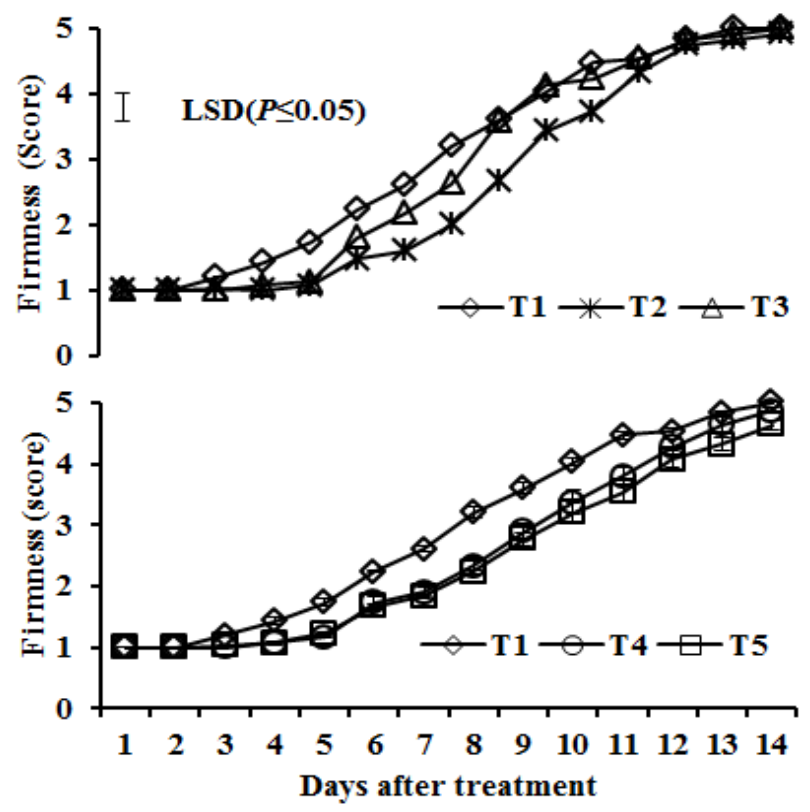

Fig. 2. Change in firmness of mango due to postharvest treatment with neem leaf and banana pulp extracts

The finding of the current study was supported by Shinde et al. (2009) who reported longer retention of acceptable firmness in mango treated with neem oil $(10 \%)$. An experiment conducted by Wijewardane and Guleria (2009) on apple fruits treated with $2 \%$ neem oil also exhibited effectiveness in retaining firmness of apple which also supports the findings of the current study.

Effects of neem leaf and banana pulp extract on weight loss of the mango: There was no significant difference among the treatments in respect of weight loss of the fruit (Fig. 3). Standard weight loss score (25\%) was crossed by control fruit (T1) at 6 DAT while the treatments T2 and T5 treated fruit took 2 days more to cross the acceptable limit. The overall loss in weight from 2 DAT to 14 DAT was $98.88 \%$. On 8 DAT, the lowest weight loss was found in $\mathrm{T} 5(27.15 \%)$, T4 $(29.19 \%)$ and $\mathrm{T} 2(29.56 \%)$ treated fruit in comparison to T1 (42.39\%).
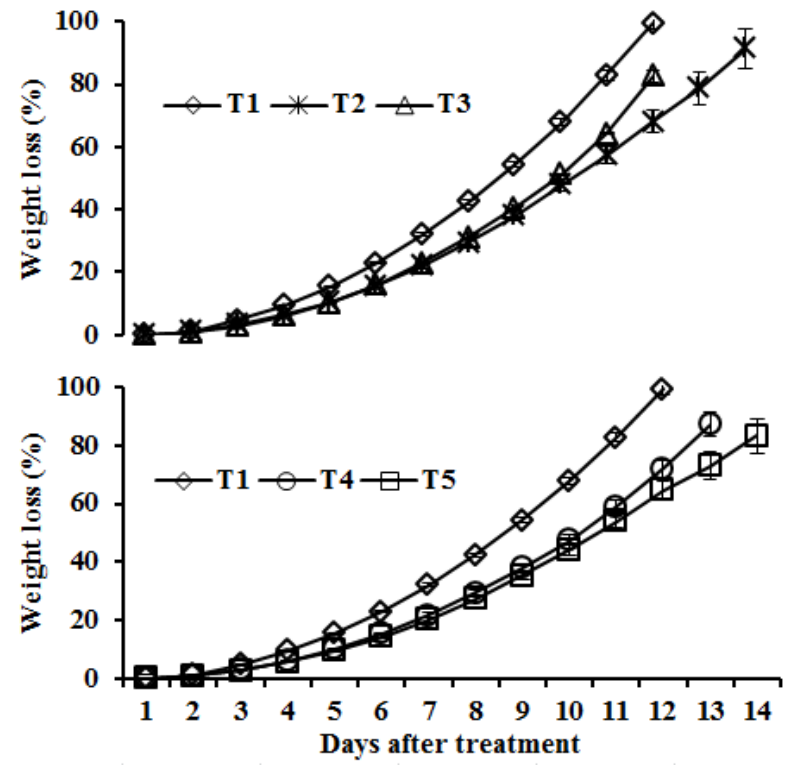

Fig. 3. Change in weight loss of mango due to postharvest treatment with neem leaf and banana Pulp extracts

The findings of Singh et al. (2000) and Shinde et al. (2009) support the findings of the current study. According to them, weight loss percent was minimized in mango fruit by using $10 \%$ neem oil. The findings of Habiba (2012) exhibited that neem extract was effective for reduction of weight loss in mango fruits which also supports the findings of the current study.

Effects of neem leaf and banana pulp extract on disease incidence and microbial infection in mango: The postharvest treatments in this study exhibited pronounced effect on disease incidence of mango during storage period (Fig. 4). The overall increase in disease incidence was $97.14 \%$ from 3 DAT to 14 DAT. Acceptable limit for disease incidence (25\%) was crossed in $\mathrm{T} 1(40 \%)$ at 7 DAT where T2 treated fruit (46.67\%) crossed that limit at 9 DAT. So, the treatments showed effectiveness in comparison to control.

Neem extract was found effective in the present study which is supported by Islam (2012). According to him, neem treated papaya fruit shows gradual increasing tendency in disease incidence. Similarly Bagwan (2001) 
reported that the treatment of banana fruits with neem extract (Azadirachta indica) for 5 minutes is most effective for controlling various postharvest diseases which also support the findings of the current study. Singh et al. (1999) also reported that the neem extracts minimized the ripe chilli fruit rot.
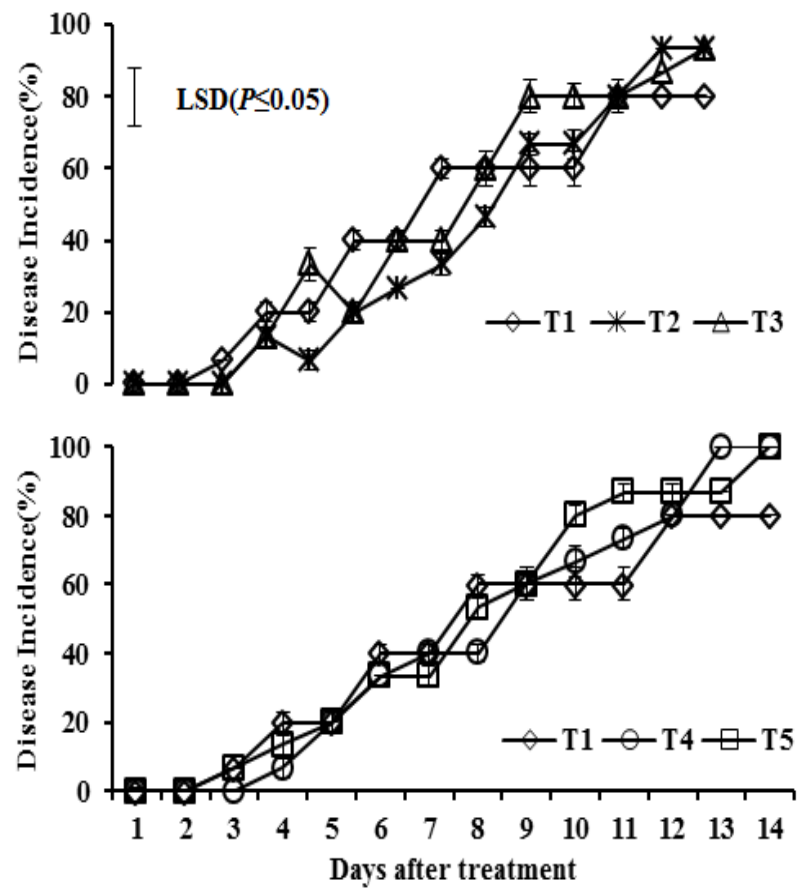

Fig. 4. Change in disease incidence (\%) of mango due to postharvest treatment with neem leaf and banana pulp extracts

Effects of neem leaf and banana pulp extract on disease severity in mango: The interaction between the treatments and DAT was significant $(P \leq 0.05)$ in respect of disease severity in mango fruit. The overall increase in disease severity was $79.59 \%$ from 1 DAT to 14 DAT (Fig. 5). The acceptable limit of disease severity (3) retained in $\mathrm{T} 2$ treated fruit for 10 days whereas in T1 treated fruits for 8 days only. However, the treated fruits did not show significant differences among them from 9 DAT.

The finding of the current study is supported by Singh $e t$ al. (1999) who stated that the disease severity was greatly influenced by neem extract treatments. According to Bagwan (2001) banana fruits treated with neem extract (Azadirachta indica) for 5 minutes was most effective for controlling postharvest disease severity of banana which also supports the findings of the current study.

Effects of neem leaf and banana pulp extract on shelf life of mango: The effect of different postharvest treatments used in the present investigation was highly significant $(P \leq 0.05)$ in respect of prolonging the shelf life of mango. The lowest shelf life was observed in T1 treated fruit (about 6.50 days) and the maximum shelf life was in T5 treated fruit (10.25 days). So, the fruits treated with T5 retained 3.75 days longer than control (Fig. 6). Other treatments also showed effective result (more than 9 days) in extending the shelf life of mango fruit during storage period.
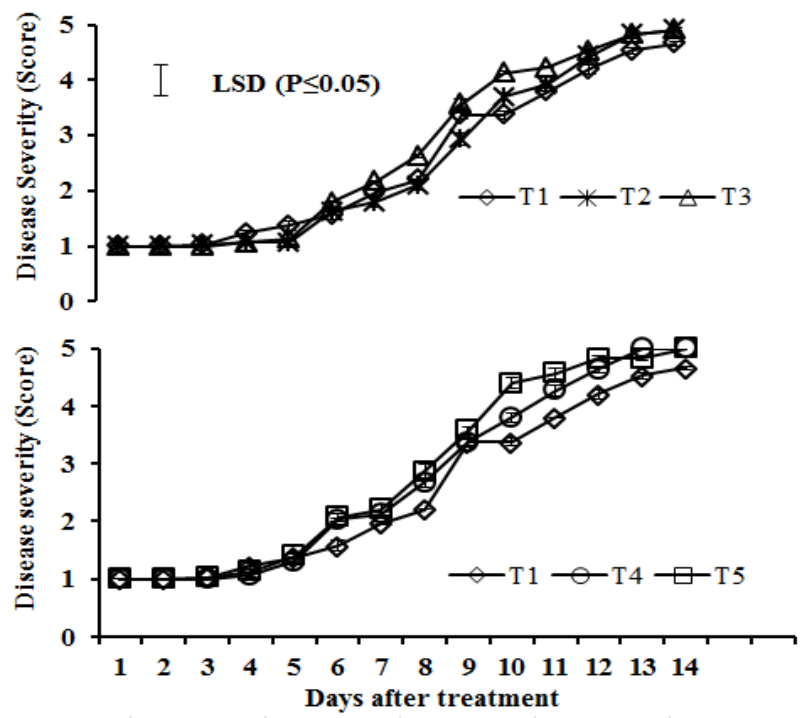

Fig. 5. Change in disease severity of mango due to postharvest treatment with neem leaf and banana pulp extracts

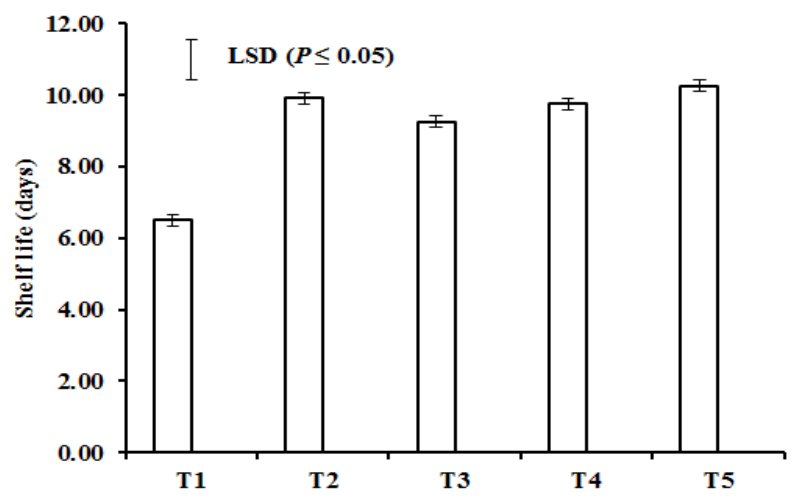

Fig. 6. Change in shelf life of mango due to postharvest treatment with neem leaf and banana pulp extracts

According to Sarkar (2012), the longer shelf life (14.87 days) was observed in neem leaf extract (10\%) treated mango fruits which support the findings from the present study. Similarly the longest shelf life (17.00 days) was observed in neem treated banana as reported by Habiba (2012). However, different botanical extracts viz., neem, garlic, and coating like sesame oil have also been reported to influence the shelf life of mango (Rodov et al., 1997).

Effects of neem leaf and banana pulp extract on total soluble solid (TSS) content of mango: A significant $(P \leq 0.05)$ change in TSS of mango was observed from the current study. The overall increase in TSS content was recorded $58.95 \%$ from 3 DAT (6.65\% brix) to 17 DAT $(16.20 \%$ brix). The highest average TSS from 3 DAT to 17 DAT was found in T1 (12.29\% brix) and the lowest was found in $\mathrm{T} 4$ (10.27\% brix). However no significant difference was observed among T2, T3 and T5 at 15 DAT (Fig. 7). 
The findings of Sarkar (2012) support the findings of the current study. According to him, neem leaf extract performed best in retaining TSS content of mango fruit. However, increase of TSS level was gradual as a result of treatment with neem extract which was proved to be most effective in retaining TSS (Malik et al., 2016).This finding is also parallel to the findings of the current study. Mango fruits treated with neem oil (10\%) proved to be most effective with respect to slower increase in TSS (Shinde et al., 2009 and Ferdowsi, 2014).

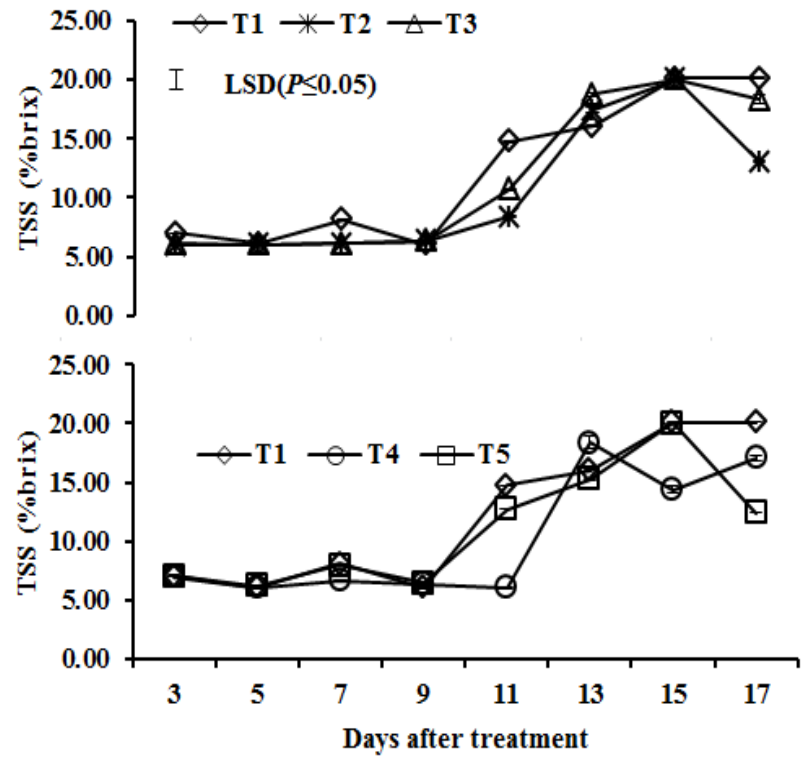

Fig. 7. Change in TSS of mango due to postharvest treatment with neem leaf and banana pulp extracts

Effects of neem leaf and banana pulp extract on titratable acidity (TA) of mango: There was no significant difference among the treatments in respect of TA (Fig. 8). The highest TA content at 15 DAT was obtained from T4 $(0.33 \%)$ while the lowest was in T2 $(0.25 \%)$. TA content of T4 $(0.33 \%)$ treated mango fruit was 1.14 fold higher than T1 $(0.29 \%)$ at 15 DAT. The overall TA reduction recorded from 3 DAT to $17 \mathrm{DAT}$ was $78.45 \%$.

The study conducted by Habiba (2012) concluded that titratable acidity decreased gradually with the progresses of storage time. According to her, the highest TA was found with neem treated Amritsagar banana fruit. Beside this, $10 \%$ neem oil proved to be most effective for mango fruit with respect to slower decrease in titratable acidity during storage period as demonstrated by Shinde et al. (2009). Mandarin fruits treated with neem leaf extract showed higher retention of titratable acidity as observed by Bhardwaj et al. (2005), Mitra et al. (1996) and Gautam and Chundawat (1989). These findings support the findings of the current study.

Effects of neem leaf and banana pulp extract on Vitamin C content of mango: A higher rate of reduction in vitamin $\mathrm{C}$ content was observed from the current study (Fig. 9). Significant reduction (66.19\%) of vitamin $\mathrm{C}$ content was observed during the storage period from $3 \mathrm{DAT}$ to $17 \mathrm{DAT}$. The best retention of Vitamin C was found in T5 $(1.73 \mathrm{mg} / 100 \mathrm{~g})$ and lowest in T3 $(0.96 \mathrm{mg} / 100 \mathrm{~g})$ at 9 DAT. The level of vitamin C in T5 treated fruit was 1.02 fold higher than T1 (1.69 $\mathrm{mg} / 100 \mathrm{~g}$ ) on 9 DAT.
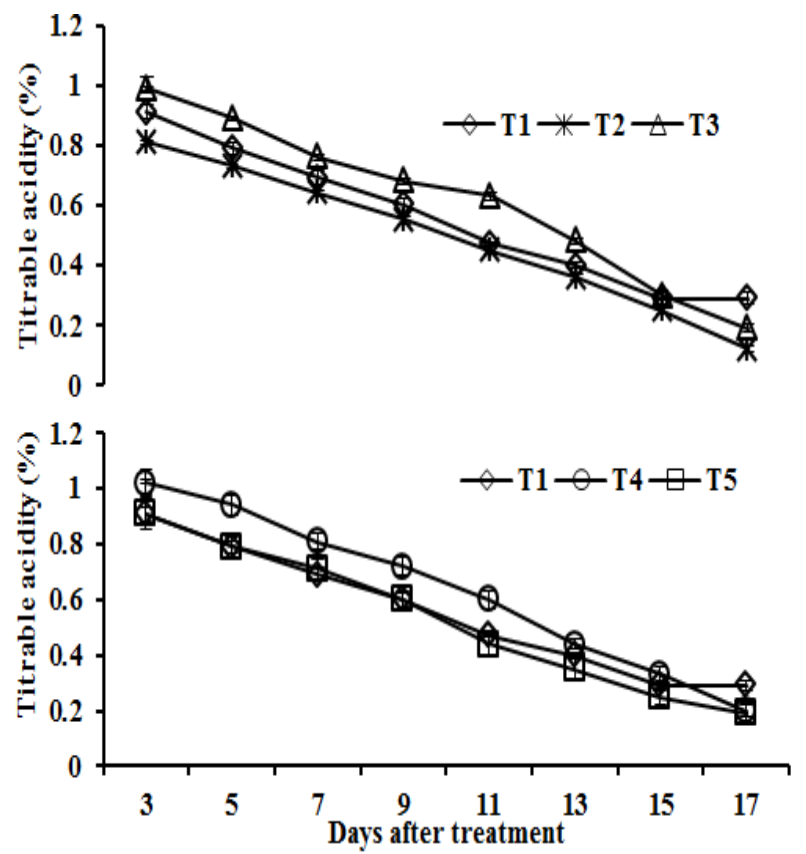

Fig. 8. Change in TA of mango due to postharvest treatment with neem leaf and banana pulp extracts
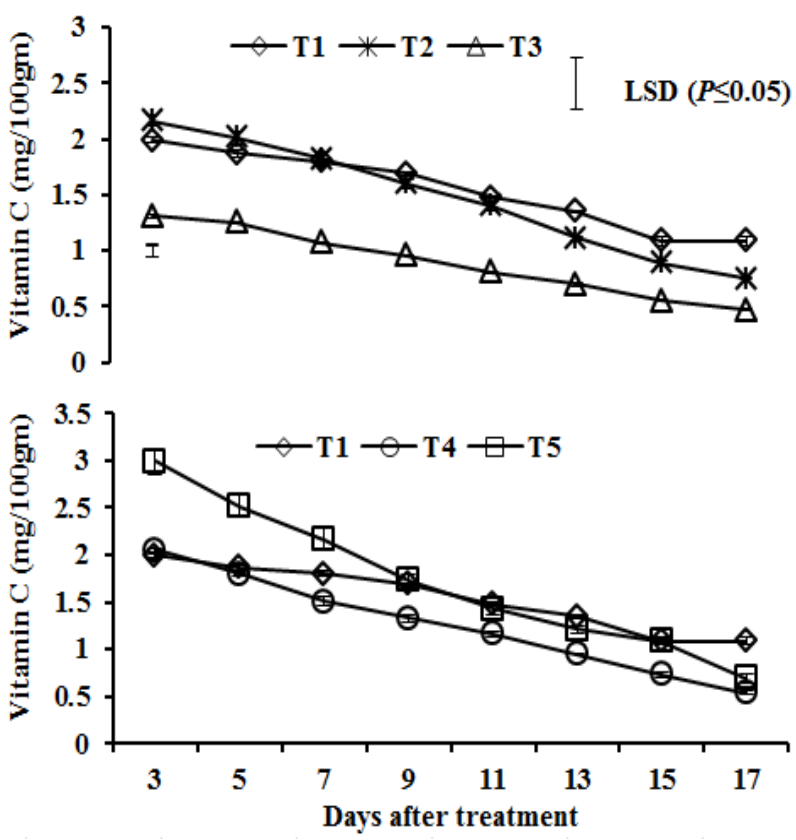

Fig. 9. Change in Vitamin $\mathrm{C}$ of mango due to postharvest treatment with neem leaf and banana pulp extracts

Vitamin C content was on the decreasing trend at varying degrees by the influence of different postharvest treatments. The findings of Malik et al. (2016) support the findings of the current study. According to them the minimum decrease in vitamin $\mathrm{C}$ was found in mango 
fruits treated with neem extracts. Similarly, Suvalaxmi and Dash (2017) found the maximum retention of ascorbic acid (23.25 mg /100 g pulp of the fruit) with $20 \%$ neem leaf extracts treatment in mango. The finding of Nisha and Jain (2014) is also supportive to the current study. They stated that minimum decrease in Vitamin C content of mango fruit was with $20 \%$ neem leaf extract as observed in cool storage.

\section{Conclusion and Recommendation}

Postharvest treatments significantly influenced the physico-chemical parameters of mango fruit under study. From the findings of the study it could be recommended that the combination of neem leaf extract $(40 \%)$ and banana pulp extract (40\%) (T5) is suitable postharvest treatment for prolonging the shelf life by maintaining better quality in Amrapali mango fruit.

The physical and microbial properties were better with the T2 treatment. When averaged over the ripening period, slower change in color and firmness (score 2.43 and 2.42 respectively), minimum incidence and severity of disease $(39.05 \%$ and score 2.53 respectively) were recorded in T2 treated mango fruit. However the T5treated fruit did not show significant difference with T2 treated fruit in respect of changes in color and firmness but showed maximum shelf life (10.25 days) and higher content of vitamin C $(1.73 \mathrm{mg} / 100 \mathrm{~g})$ during this period. After two weeks of storage maximum average TA $(0.63 \%)$ and minimum TSS (1.27\% brix) was found in T4 treated mango fruit, though the minimum weight loss $(27.36 \%)$ was recorded in T3 treated fruit without any significant difference with the fruit treated with $\mathrm{T} 4$ and $\mathrm{T} 5$.

\section{References}

Ahmed M.S. and Singh S. 2000. Studies on extension of storage life of Amrapali mango. Orissa Journal of Horticulture, 28(2): 7376.

Alleyne, X. and Hagenmaier, R.D. 2000. An alternative formulation for coating apples. HortScience, 35(4):691-693.

Bagwan, N.B. 2001. Anthracnose of banana fruits and its management with plant extracts. Aerobiology, Mycology and Pathology Laboratory, Department of Botany, M.U. College, India Current Research University of Agriculture Science Bangalore, 30(11\&12): 197-198.

Bhardwaj, R.L., Sen N.L. and Mukherjee S. 2005. Effect of benzyladenine on physico-chemical characteristics and shelf life of mandarin cv. Nagpur Santra. Indian Journal of Horticulture, 62: 181-183.

Braimah, H., Anno-Nyarko, E.O., Nkansah, G.O. and Nutsugah, S. K. 2010. Mango production in Ghana. Ghana Journal of Agricultural Science, 18: 24-27.

Chaturvedi, R., Razdan, M.K. and Bhojwani, S.S. 2003. Production of haploids of neem (Azadirachta indica A. Juss.) by anther culture. Plant Cell Reports, 21:531-537. PMid:12789427

Dang, K.T.H., Singh, Z. and Swinny, E.E. 2008. Edible coating influence fruit ripening, quality, and aroma biosynthesis in mango fruit. Journal of Agriculture and Food Chemistry, 56: 1361-1370. https://doi.org/10.1021/jf072208a PMid:18247535

FAO (Food and Agricultural Organization of the United Nations). 2010. Web site http:/www.fao.org, accessed on 2013.

Ferdowsi, M.Z. 2014.Effect of Plant Extracts and Heat Treatment on Shelf life and Quality of Mango. An MSc Thesis submitted to the Department of Horticulture, Bangladesh Agricultural University, Mymensingh.

Gautam, S.K., Chundawat, B.S. 1989. Effects of various postharvest treatments on biochemical change in sapota cv. Kalipatti-1. Indian Journal of Horticulture, 46:310-319.

Gomez, K.A. and Gomez, A.A. 1984. Statistical Procedures for Agricultural Research. Jon Wiley and Sons. Inc, New York, pp. 67-215.

Habiba, U. 2012. Effects of different plant extracts on shelf life and quality of banana. An MSc Thesis submitted to the Department of Horticulture, Bangladesh Agricultural University, Mymensingh.

Haq, A. 2002. Package for mango production, postharvest techniques and its export prospects, Mango Res. Inst. Shajabad, pp. $1-15$. PMid:12061796

Hassan, M.K. 2010. Final Report: Postharvest loss Assessment: A Study to Formulate Policy for Postharvest Loss Reduction of fruits and Vegetables and Socio-Economic Uplift of the Stakeholders (A Research Project Funded by USAID and EC, and Jointly implemented by FAO and FPM of the Ministry of Food and Disaster Management (MoFDM) under the National Food Programme Capacity Strengthening Programme NFPCSP).

IRRI (International Rice Research Institute). 2013. Biometrics and Breeding Informatics. (Available from www. Bbi.irri.org on august, 2017).

Islam, M.S. 2012. Effects of plant extracts on the extension of shelf life of papaya without affecting the postharvest quality of fruits. An MSc Thesis submitted to the Department of Horticulture, Bangladesh Agricultural University, Mymensingh.

Jacobi, K.K., Macrae E.A. and Hetherington S.E. 2001.Postharvest heat disinfestation treatments of mango fruits. Scientia Horturae, 89(3): 171-193. https://doi.org/10.1016/ S03044238(00)00240-5

Khan, S.A. and Singh, Z. 2008. 1-Methylcyclopropene Application and Modified Atmospheric Packaging Affect Ethylene Biosynthesis, Fruit Softening and Quality of 'Tegan Blue' Japanese Plum during Cold Storage, Journal of American Society of Horticultural Science, 133(2): 290-299.

Knab, N.R. 2013. Effects of edible- non edible coating materials on shelf life of banana, M S thesis, Department of Horticulture, BAU, Mymensingh.

Kumar, K.P.S, Bhowmik, D., Duraivel, S. and Umadevi, M. 2012. Traditional and Medicinal Uses of Banana. Journal of Pharmacognosy and Phytochemistry, 1(3): 51- 63.

Majumdar, B.C. and Majumdar, K. 2003. Methods of Physico Chemical Analysis of Fruits. Daya Publishing House, New Delhi.

Malik, A.A. Ahmed, N. and Kaul, R. 2015.Effect of Postharvest Application of Plant Extracts on Physical Parameters and Shelf Life of Guava. Asian Agri-History, 19(3):185-193.

Malik A.A., Ahmed N., Babita and Chauhan H.P. 2016. Plant Extracts in Post-Harvest Disease Management of Fruits and Vegetables. Journal of Food Processing and Technology. 7: 592. https://doi.org/10.4172/2157-7110.1000592

Mia, B. 2003. Studies on postharvest behavior of papaya. An MS thesis submitted to Department of Horticulture, BAU, Mymensingh, pp. 40-96.

Mitra, S., Harangi, A.B.S. and Kar, N. 1996. Effects of polyethylene at low temperature and different growth regulators at ambient temperature on change in total soluble solids, total sugars, titratable acidity and ascorbic acid content of litchi during storage. Environmental Ecology, 14:538-542.

Nisha, G., and Jain, S.K. 2014. Storage Behavior of Mango as Affected By Postharvest Application of Plant Extracts and Storage Condition. Journal of Food Science and Technology, 51(10): 2499-2507. https://doi.org/10.1007/ s13197-012-0774-0 PMid:25328189 PMCid:PMC4190223

Pervin, R. 2016. Effect of Combined Botanical Extracts on Postharvest Performances of Bitter Gourd (Momordica charantia). B. Sc. Thesis submitted to Dept. of Food and Nutrition, 
Khulna City Corporation Women's College (Affiliated to Khulna University), Khulna, Bangladesh.

Ranganna, S. 1979. Manual of Analysis of Fruit and Vegetable products. Tata McGraw-Hill Pub. Co. Ltd., New Delhi, p. 634.

Rodov, V., Fishman, S., Asuncion, R.D., Peretz, J. and Yehoshua, S.B 1997. Modified atmosphere packaging (MAP) of Tommy Atkins mango in perforated film. Acta Horticulture. 455: 654-661. https://doi.org/10.17660/ActaHortic.1997.455.84

Sarkar, P.K., 2012. Effects of different post-harvest treatments on physico-chemical chages and quality of mango. An MSc Thesis submitted to Department of Horticulture, Bangladesh Agricultural University, Mymensingh. pp. 65.

Schmutterer, H. 1990. Properties and potential of natural pesticides from neem tree, Azadirachta indica. Annual Review of Entomology, 35: 2719. https://doi.org/10.1146/annurev.en. 35.010190 .001415 PMid:2405771

Shafique, M.Z. 2006. Studies on the physiological and biochemical composition of different mango cultivars at various maturity levels. Bangladesh Journal of Science and Industrial Research.41: 101-108.

Shinde, G.S., Viradia, R.R., Patil, S.A. and Kakade, D.K. 2009.Effect of natural plant extracts and wrapping materials on storage behavior of mango (Mangifera indica L.) cv. Kesar. International Journal of Agricultural Science, 5(2): 420423.
Singh, H.V., Desai, K. and Singh, P.P 1999. Evaluation of some plant extracts for control of Colleetotrichum capsici the causal agent of chilli anthracnose. Mora Institute of Technology, perlis campus, Malaysia. 12: 131-138.

Singh, J.N., Acharya, P. and Singh, B.B. 2000. Effect of GA3 and plant extracts on storage behaviour of mango (Mangifera indica) cv. Langra. Haryana Journal of Horticultural Sciences.29: 3-4.

Srivastava, R.P. (ed.) 2003. Biopesticides and Bioagents in Integrated Pest Management of Agricultural Crops. International Book Distributing Co., Lucknow, Uttar Pradesh, India. 334 pp.

Suvalaxmi, P. and Dash, D.K. 2017. Influence of Post-Harvest Application of Plant Extracts and Storage Condition on Post-Harvest Physiology of Mango cv. Amrapali. International. Journal of Curent Microbiology and Applied Science, 6(8): 1429-1440.

Ullah, M.H. 2007.Effect of postharvest treatments on the prolongation of shelf life of banana. Master's thesis, Bangladesh Agricultural University, Mymensingh, Bangladesh.

Wijewardane, R.M.N.A. and Guleri, S.P.S. 2009.Combined Effects of Pre-cooling, Application of Natural Extracts and Packaging on the Storage Quality of Apple (Malus domestica) cv. Royal Delicious. Tropical Agricultural Resources, 21(1): 10-20. https://doi.org/10.4038/tar.v21i1.2582 